\title{
Intracardiac echocardiography use during electrophysiology procedures to guide catheter ablations - single center experience from General Hospital Zadar
}

\author{
Albino Jović, Ante Anić*, Zoran Bakotić, Marin Bištirlić \\ Zadar General Hospital, Zadar, Croatia
}

Background: The purpose is to give an overview of application of intracardiac echocardiography (ICE) in routine electrophysiology (EP) practice. Validation of ICE in improving the safety of transseptal puncture is shown separately.

Methods and Results: During the observed period (11/2009-03/2013) ICE was used in 83 procedures. 75 were AF ablations in which ICE was used initially to facilitate transseptal puncture and later on to check catheter contact with tissue and to monitor for the complications (pericardial effusion, thrombus formation at materials used in the left atrium). There were 4 left atrial tachycardias ablations, 2 left ventricular tachycardias and 1 accessory pathway and AVNRT ablation assisted by ICE.
Conclusion: ICE is essential tool in EP lab. Its use not only improves safety yet efficacy through helping catheter navigation and validating the catheter-tissue contact.

KEYWORDS: intracardiac echocardiography, electrophysiology procedures, ablation, transseptal puncture, cathetertissue contact.

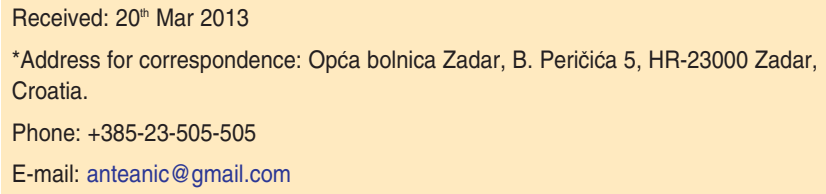

*Address for correspondence: Opća bolnica Zadar, B. Peričića 5, HR-23000 Zadar, Croatia.

Phone: +385-23-505-505

E-mail: anteanic@gmail.com

\section{Literature}

1. Hijazi ZM, Shivkumar K, Sahn DJ. Intracardiac echocardiography (ICE) during interventional \& electrophysiological cardiac catheterization. Circulation. 2009 ;119(4):587-96. 2. Daoud EG, Kalbfleisch SJ, Hummel JD. Intracardiac echocardiography to guide transseptal left heart catheterization for radiofrequency catheter ablation. J Interv Card Electrophysiol. 2010;28(3):167-84.

3. Banchs JE, Patel P, Naccarelli GV, Gonzalez MD. Intracardiac echocardiography in complex cardiac catheter ablation procedures. J Cardiovasc Electrophysiol. 1999;10(3):35863.

4. Anić A. Catheter ablation for atrial fibrillation. Cardiol Croat. 2010;5(3-4):33-6. 